\title{
Long-term Response of Early Maturing Peach Trees to Postharvest Water Deficits
}

\author{
R.S. Johnson, D.F. Handley, and T.M. DeJong \\ Department of Pomology, University of California Kearney Agricultural Center, Parlier, CA 93648 \\ Additional index words. Prunus persica, water stress, irrigation
}

\begin{abstract}
Early maturing peach trees [Prunus persica (L.) Batsch cv. Regina] growing on a deep sandy loam soil were subjected to three levels of postharvest irrigation over 4 years. The control treatment was irrigated with $\approx 10$ to $15 \mathrm{~cm}$ of water at 2- to 3 -week intervals, the medium treatment received a single irrigation $(20$ to $30 \mathrm{~cm})$ in early August, and the dry treatment was not irrigated between early to mid-June and mid-October. All received a predormancy irrigation of 10 to $15 \mathrm{~cm}$ in mid- to late October. Flower and fruit density were greater in the dry treatment than the control. The occurrence of double fruit was also greatly increased in the dry treatment but not in the medium treatment, when compared with the control. After normal commercial hand thinning, yields and fruit size were no different among the three treatments over all 4 years. Vegetative growth as measured by dormant pruning weights, trunk radial growth, and canopy shaded area was reduced in the dry treatment, but there was no indication of progressively declining vigor. Soil moisture determinations indicate that water use by the control occurred mainly in the upper soil profile. In the dry treatment, as the upper profile dried, water was extracted progressively deeper, down to at least $300 \mathrm{~cm}$. The main disadvantage of severe postharvest water stress was the substantial increase of double fruits.
\end{abstract}

There are numerous early maturing stone fruit cultivars grown in the Central Valley of California that ripen before mid-June. For these cultivars, $\approx 75 \%$ of seasonal evapotranspiration occurs after harvest and is met almost totally by irrigation. Reduced water applicationsduring this period would be desirable to conserve water, especially in a drought situation, and might provide a method of controlling excessive vegetative growth.

Potential problems arise, however, in relation to the development of the next year's crop and to long-term tree health and productivity. Flower bud initiation and development occur during this period (Ryugo, 1988; Tufts and Morrow, 1925). Research by Brown (1953), Jackson (1969), and Uriu (1964) indicate that postharvest water stress in apricots (Prunus armeniaca L.) has detrimental effects on flower bud development and subsequent fruiting. Hartmann and Panetsos (1961) describe similar results with olives (Olio europaeu L.). However, other studies of deficit irrigation in peach (Garcia, 1980), citrus (Moreshet et al., 1983), litchi (Litchi sinensis Sonn.) (Nakata and Suehisa, 1969), and pear (Pyrus communis L.) (Mitchell et al., 1984) demonstrate increased return bloom in deficit-irrigated trees.

The effect of prolonged water stress on overall tree growth and health is also not known. It mature peach trees, shoot extension occurs mainly in the spring (DeJong et al., 1987) so postharvest water stress would only have a minor effect on this component of growth (Veihmeyer, 1975). A small decrease in shoot growth might be beneficial if it reduces pruning time or improves light penetration into the canopy, especially with early maturing cultivars, which are characterized by vigorous vegetative growth. Of greater concern would be cumulative effects such as reduction in reserves and root growth, cavitation of xylem vessels (Tyree and Dixon, 1986), or development of disease (Bertrand et al., 1976), which might lead to a progressive decline in vigor. Severe water stress can lead to defoliation, limb dieback, and tree death (Proebsting and Middleton, 1980).

In the initial year of this study (Larson et al., 1988), two levels of postharvest deficit irrigation substantially reduced sto-

Received for publication 16 Oct. 1991. Accepted for publication 20 Apr. 1992. The cost of publishing this paper was defrayed in part by the payment of page charges, Under postal regulations, this paper therefore must be hereby marked advertisement solely to indicate this fact. matal conductance, transpiration, and leaf water potential compared with a well-watered control. An inhibition of secondary growth, indicated by lower pruning weights and reduced trunk radial growth in the dry treatment, was also noted. Tree response in the year following deficit irrigation included increased flower density and fruit set in the driest treatment, but no significant differences in fruit yield or fruit size among treatments following commercial thinning. No premature defoliation, limb dieback, or reduction in yield occurred in the severe water stress treatment, which received no irrigations during the hottest and driest part of the season. We hypothesized that trees in this treatment were extracting water from deep within the soil profile. Under deficit irrigation, a shift in water extraction patterns from shallow to deep in the soil profile has been reported for apples (Malus domestica Borkh.) (Levin et al., 1973) and peaches (Garnier et al., 1986). Levin et al. (1973) also reported a concomitant shift in root distribution and found extraction to be proportionate to root density.

The objective of this study was to assess long-term effects of continued postharvest deficit irrigation treatments (4 years) on tree growth, bloom density, productivity, soil water extraction patterns, and root distribution.

\section{Materials and Methods}

Site. A 1.4-ha block of 'Regina' peach trees located at the Univ. of California Kearney Agricultural Center, Parlier, was used for this study (same trees as used by Larson et al., 1988). Tree spacing was $6.1 \times 6.1 \mathrm{~m}$. The soil is a fine sandy loam overlying a dense hardpan at depths from 270 to $300 \mathrm{~mm}$. Mean annual rainfall for 1983-86 was $260 \mathrm{~mm}$, with no significant rainfall during the postharvest period between mid-June and mid-October.

Treatments. Before harvest each year, all trees received the same standard commercial practice of furrow irrigation every 2 to 3 weeks. Harvest dates varied from 31 May to 5 June in 1986 and 13 to 28 June in the other 3 years. Postharvest irrigation treatments initiated in 1983 were: $\approx 10$ to $15 \mathrm{~cm}$ of water applied at 2- to 3-week intervals (control), one 20- to 30- $\mathrm{cm}$ irrigation applied in early August (medium) and no irrigations from harvest until mid-October (dry). All treatments received a predormancy irrigation of $\approx 10$ to $15 \mathrm{~cm}$ in mid-October. In 1986 the 
control treatment was not irrigated between 5 Sept. and 26 Oct., and the predormancy irrigation for all treatments was delayed until 26 Oct. due to the existence of open trenches for root counts. Furrow irrigation was used for all treatments.

The field was set up as a split-plot design with two replications of each irrigation treatment as the main plot. Subplots consisted of two trees each on three rootstocks, 'Lovell,' 'Nemaguard', and 'Nemared', for a total of 36 treatment trees. Main plot and subplot error terms were not statistically different from each other and were therefore pooled to obtain a more reliable estimate of an error term with more degrees of freedom. There were no significant rootstock effects on any of the characteristics measured, so only irrigation effects will be presented.

Flowering and yield measurements. Bloom density was measured at full bloom in $1984-87$ by counting flowers on nine 30to 50-cm-long, randomly tagged, horizontal fruiting shoots in the top of each experimental tree. Total and double fruitlets remaining on the same shoots were counted before thinning in April each year. Flower and fruit counts were expressed per meter of shoot length rather than per trunk or scaffold crosssectional area. The severe pruning of early season peaches makes the latter term inappropriate for this experiment.

Fruit was harvested based on maturity (ground color) in two to three sequential harvests in June each year. Total yield was measured for each tree. Mean fruit weight was estimated by counting and weighing a sample of about half the fruit from each tree. In 1985 and 1987, fruit with split pits and double fruit from this sample were also counted.

Vegetative growth measurements. Pruning weights were determined immediately following commercial hand pruning during the dormant season of each year. Trunk radial growth was measured with a microdendrometer (A.B. Pulco, Lund, Sweden), which rested on three screws imbedded well within the heartwood of the trunk. Measurements were discontinued after Mar. 1986 because growth on several trees extended beyond the limits of the microdendrometer.

Canopy shaded area was estimated in Sept. 1986 for all test trees on 'Nemaguard' and 'Nemared' rootstocks. A large tarpaulin divided into $400-\mathrm{cm}^{2}$ squares was placed under the tree between 11:00 AM and 1:00 PM and the total number of shaded squares counted. In Oct. 1986, 60 leaves from each tree were sampled for leaf area and dry weight to calculate specific leaf weight.

In Oct. 1986, the trench profile method (Bohm, 1979) was employed to examine root distribution in the soil profile. Trenches $240 \mathrm{~cm}$ deep and $300 \mathrm{~cm}$ long were dug next to three 'Nemaguard' trees in each treatment. They were dug on a diagonal to the tree row, and the center of each trench was $\approx 45 \mathrm{~cm}$ from the trunk. A $210 \times 210 \mathrm{~cm}$ area of the trench wall was divided into 49 equal sections of $30 \times 30 \mathrm{~cm}$ each. Total root counts were made in each section and averaged together horizontally to obtain root density by depth.

Gumming from the trunks and scaffolds of the trees was quantified in 1986 by measuring the total length of gum exudate on each test tree.

Soil water depletion measurements. In 1985, neutron probe access tubes were installed within the furrow and $1 \mathrm{~m}$ from a tree trunk to a depth of $3 \mathrm{~m}$ at three locations in each treatment block. Volumetric water content was measured in all tubes with a Campbell Pacific neutron probe at $30-\mathrm{cm}$ depth intervals immediately preceding and several days after each treatment irrigation. Measurements were made from 25 July-15 Oct. 1985 and from 1 Apr.-15 Oct. 1986. Available water content was calculated by subtracting the water content measured at $1.5 \mathrm{MPa}$ from each reading. The relationship between available water content and soil matric potential for a nearby field of the same soil series was obtained (Table 1).

\section{Results}

Flowering and yield responses. Flower density in the dry plots was significantly greater than in the control in all 4 years (Fig. 1). The medium stress treatment was generally intermediate. Flower density in the control varied from year to year but was fairly constant, whereas in the dry treatment it increased in each of the 4 years. Fruit density before commercial thinning showed about the same pattern as flower density, indicating that percent set was not affected by the treatments (Fig. 1).

Total yield for each year accumulated over the 4 years was not statistically different among treatments (Table 2). However, there were some trends in individual years; in the control the yield was lowest in 1986, apparently related to the low flower density in that year (Fig. 1). The dry treatment yield was lowest in 1987 due to low fruit counts resulting from heavy pruning and to the many double fruits that had to be thinned off the tree. Average fruit weight was not significantly affected by the water stress treatments from the previous season.

The most striking effect of postharvest water stress on flowering or fruit yield was the dramatic increase in the amount of double fruit at thinning (Fig. 2). The percent doubling varied considerably from year to year. In 1985 it was as high as 34\% in the dry plots. Even after careful hand thinning to remove defective fruit, almost $4 \%$ of the harvested fruit were still doubles (Table 2). The two postharvest irrigations applied to the

Table 1. Available water content at various soil matric potentials for a fine, sandy loam soil at the Kearney Agricultural Center, Parlier, Calif. (D.W. Grimes, personal communication).

\begin{tabular}{cc}
\hline \hline $\begin{array}{c}\text { Available water } \\
\text { content } \\
(\mathrm{cm} / 75 \mathrm{~cm})\end{array}$ & $\begin{array}{c}\text { Soil matric } \\
\text { potential } \\
(\mathrm{MPa})\end{array}$ \\
\hline 14.9 & 0.01 \\
9.2 & 0.03 \\
6.5 & 0.07 \\
5.7 & 0.10 \\
1.3 & 0.30 \\
1.0 & 0.50 \\
0.4 & 1.00 \\
0.0 & 1.50 \\
\hline
\end{tabular}

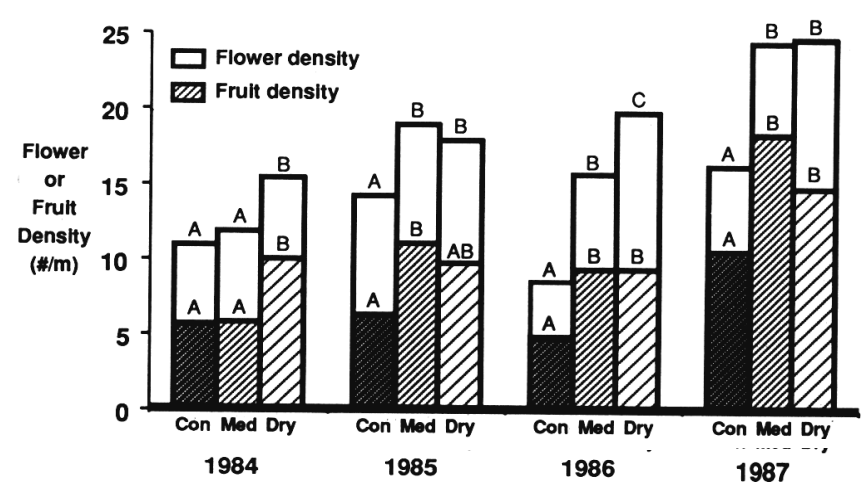

Fig. 1. Effect of postharvest irrigation treatments on flower and fruit density of 'Regina' peach. Bars represent means of nine shoots on each of 12 trees per treatment. Means separation within years and flower or fruit density by Duncan's multiple range test $(P=0.05)$. 


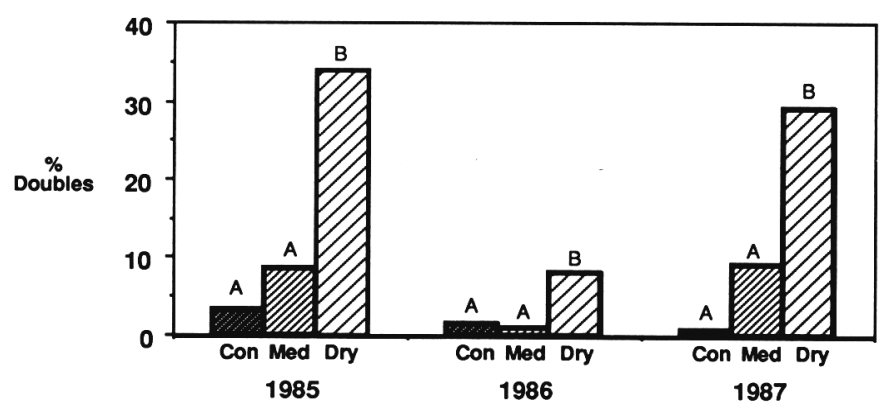

Fig. 2. Effect of postharvest irrigation treatments on percentage of 'Regina' peach fruit at thinning time that are double fruit. Bars represent means of nine shoots on each of 12 trees per treatment. Mean separation within years by Duncan's multiple range test ( $P=$ $0.05)$.

Table 2. Effect of postharvest irrigation treatments in 1984 and 1986 on the Percentage of double and split peach fruit in 1985 and 1987.

\begin{tabular}{cccccc}
\hline \hline \multirow{2}{*}{$\begin{array}{c}\text { Fruit defects } \\
\text { at harvest }\end{array}$} & Year & \multicolumn{4}{c}{ Treatment } \\
\cline { 3 - 6 } Yield (kg/tree) & 1984 & 98.9 & 107.8 & 120.1 & NS \\
& 1985 & 128.9 & 136.0 & 127.8 & NS \\
& 1986 & 47.7 & 85.2 & 81.1 & NS \\
& 1987 & 83.4 & 101.9 & 77.7 & NS \\
& $1984-87$ & 358.9 & 430.9 & 406.7 & NS \\
Fruit wt (g) & 1984 & 180.4 & 184.9 & 181.4 & NS \\
& 1985 & 160.4 & 159.6 & 158.2 & NS \\
& 1986 & 156.5 & 147.3 & 144.6 & NS \\
& 1987 & 158.9 & 159.6 & 164.2 & NS \\
Doubles (\%) & 1985 & $0.5 \mathrm{a}$ a & $0.4 \mathrm{a}$ & $3.7 \mathrm{~b}$ & $* * *$ \\
& 1987 & $0.1 \mathrm{a}$ & $1.4 \mathrm{~b}$ & $2.1 \mathrm{c}$ & $* * *$ \\
Splits (\%) & 1985 & $1.4 \mathrm{ab}$ & $0.9 \mathrm{~b}$ & $1.8 \mathrm{a}$ & $*$ \\
& 1987 & 0.5 & 1.0 & 1.6 & $\mathrm{NS}$ \\
\hline
\end{tabular}

${ }^{2}$ Mean separation within rows by Duncan's multiple range test ( $P=$ $0.05)$.

${ }^{y}$ Statistics performed on transformed data.

medium treatment were sufficient to substantially reduce the amount of doubling both at thinning and at harvest the following year.

Other measures of fruit quality showed little difference among treatments. In 1985, the dry treatment had more split pits than the medium treatment, but the differences were very small (Table 2). There were no differences in firmness, soluble solids concentration, or titratable acidity measured in 1987 (data not shown).

Vegetative growth responses. Although there was a trend toward a reduction in pruning weights with increasing postharvest stress in all 4 years, there were statistical differences only in 1984 and 1986 (Table 3). Pruning weights from the dry plots averaged $\approx 21 \%$ less than those of the control over the period of the experiment.

Trunk radial growth of the trees in the dry plots during the first $2 \frac{1}{2}$ years of the study was reduced by $38 \%$ compared with that of the controls. There was no significant decrease in radial growth of trees in the medium treatment compared with those in the control plots.

The area shaded by the canopy of control trees in Sept. 1986 was significantly larger than that of trees in the dry treatment. Specific leaf weight of trees in the medium and dry treatments was increased relative to control trees (Table 3).

Root profile data indicate a trend toward decreased root den-
Table 3. Effect of postharvest irrigation treatments on vegetative variables for peach trees over 4 years.

\begin{tabular}{|c|c|c|c|c|c|c|}
\hline \multirow[b]{2}{*}{ Factor } & \multirow[b]{2}{*}{ Date } & \multicolumn{3}{|c|}{ Treatment } & \multirow{2}{*}{\multicolumn{2}{|c|}{$\begin{array}{r}\text { Signif } \\
\text { icance }\end{array}$}} \\
\hline & & Control & Medium & Dry & & \\
\hline \multirow{4}{*}{$\begin{array}{c}\text { Pruning wt } \\
\text { (kg/tree) }\end{array}$} & & & & & & \\
\hline & 1983 & 28.2 & 26.8 & 25.4 & & $\begin{array}{l}\mathrm{NS} \\
* *\end{array}$ \\
\hline & $\begin{array}{l}1984 \\
1985\end{array}$ & $\begin{array}{l}31.5 \mathrm{a} \\
27.4\end{array}$ & $\begin{array}{l}27.0 \mathrm{a} \\
26.6\end{array}$ & 24.5 & & NS \\
\hline & 1986 & $35.8 \mathrm{a}$ & $28.9 \mathrm{~b}$ & $25.2 \mathrm{~b}$ & & $* *$ \\
\hline $\begin{array}{l}\text { Trunk radial } \\
\text { growth }(\mathrm{mm})\end{array}$ & $7 / 83-3 / 86$ & $15.3 \mathrm{a}$ & $13.2 \mathrm{a}$ & $9.5 \mathrm{~b}$ & & $*$ \\
\hline $\begin{array}{l}\text { Canopy shaded } \\
\text { area }\left(\mathrm{m}^{2}\right)\end{array}$ & $9 / 86$ & $24.1 \mathrm{a}$ & $22.1 \mathrm{ab}$ & 20.9 & $\mathrm{~b}$ & $*$ \\
\hline $\begin{array}{l}\text { Specific leaf wt } \\
\left(\mathrm{mg} \cdot \mathrm{cm}^{-2}\right)\end{array}$ & $10 / 86$ & $5.2 \mathrm{a}$ & $6.2 \mathrm{~b}$ & 6.4 & b & $* *$ \\
\hline $\begin{array}{l}\text { Gumming } \\
\quad \text { (length along } \\
\text { scaffolds, cm) }\end{array}$ & ) $10 / 86$ & $17.3 \mathrm{a}$ & $23.5 \mathrm{a}$ & 106.7 & $\mathrm{~b}$ & ** \\
\hline
\end{tabular}

${ }^{2}$ Mean separation within rows by Duncan's multiple range test ( $P=$ $0.05)$.

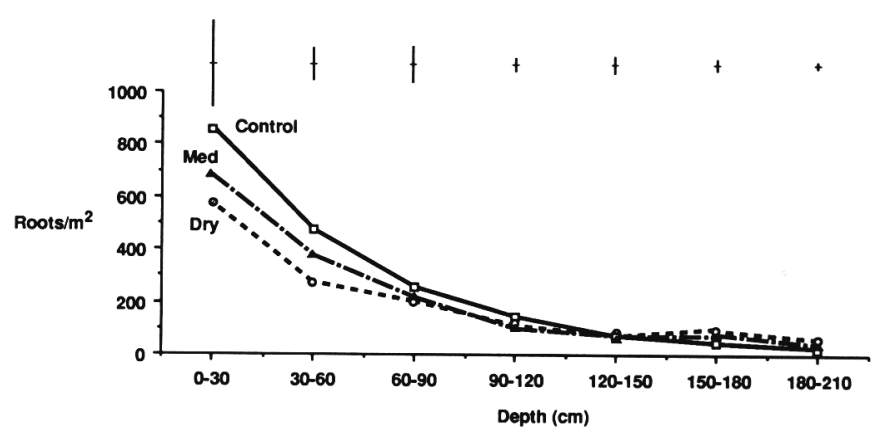

Fig. 3. Root densities within vertical $30-\mathrm{cm}$ increments of the soil profile under 'Regina' peach trees with 'Nemaguard' rootstock in response to 4 years (1983-86) of postharvest irrigation treatments. Symbols represent means of seven $900-\mathrm{cm}^{2}$ sections from each of three trees per treatment. Error bars indicate SE of the mean for each depth. At the 30 to $60-\mathrm{cm}$ depth, trend analysis indicated a significant $(P=0.05)$ linear trend among irrigation treatments.

sities at shallow soil depths in trees exposed to greater water stress and slightly higher root densities deeper in the soil profile (Fig. 3). As is often the case with root measurements in the field, the data were generally too variable to determine if these trends were significant. Using trend comparisons (Little and Hills, 1978), there was a significant linear trend over irrigation treatments at the $30-$ to $60-\mathrm{cm}$ depth.

No trees died during the course of the experiment, and premature leaf fall was never observed. In 1986, there was some gumming produced on the trunks and lower scaffolds of the trees (Table 3). Harvest was 2 weeks earlier than normal that year, leading to a longer duration of water stress. Maximum temperatures were also generally higher than normal (Table 4). The gumming occurred rather extensively on trees in the dry treatment and only sporadically on those in the medium and control treatments. Gumming did not reoccur in 1987, and the trees appeared to be normal and healthy. Over the 4 years of this experiment, there were no indications that postharvest water stress led to a decline in tree health.

Soil water depletion. The patterns of soil water depletion, as monitored with the neutron probe, indicated preferential water extraction from upper soil layers under well-watered conditions. 
Table 4. Average maximum temperatures at the Kearney Agricultural Center, Parlier, Calif., during 2-week periods for the late spring and summer seasons of 1984-86.

\begin{tabular}{|c|c|c|c|c|c|c|c|c|c|}
\hline \multirow[b]{3}{*}{ Year } & \multicolumn{9}{|c|}{ Temp $\left({ }^{\circ} \mathrm{C}\right)$} \\
\hline & \multicolumn{2}{|c|}{ May } & \multicolumn{2}{|c|}{ June } & \multicolumn{2}{|c|}{ July } & \multicolumn{2}{|c|}{ August } & September \\
\hline & $1-15$ & $16-31$ & $1-15$ & $16-30$ & $1-15$ & $16-31$ & $1-15$ & $16-31$ & $1-15 \quad 16-30$ \\
\hline 1984 & 30.2 & 35.4 & 30.9 & 37.2 & 41.5 & 37.3 & 37.7 & 37.7 & $38.4 \quad 34.7$ \\
\hline 1985 & 28.8 & 29.6 & 34.7 & 37.5 & 39.3 & 37.2 & 35.9 & 36.2 & $28.6 \quad 31.7$ \\
\hline 1986 & 26.9 & 33.9 & 34.3 & 36.1 & 37.5 & 35.2 & 40.1 & 37.6 & $34.5 \quad 25.6$ \\
\hline \multicolumn{10}{|l|}{$30 \mathrm{yr}$} \\
\hline $\operatorname{avg}^{2}$ & 26.5 & 29.7 & 31.2 & 34.4 & 35.9 & 37.4 & 36.4 & 34.3 & $33.5 \quad 31.4$ \\
\hline
\end{tabular}

${ }^{2}$ Based on the years 1951-80 at the Fresno Air Terminal, $\approx 40 \mathrm{~km}$ from Kearney Agricultural Center.

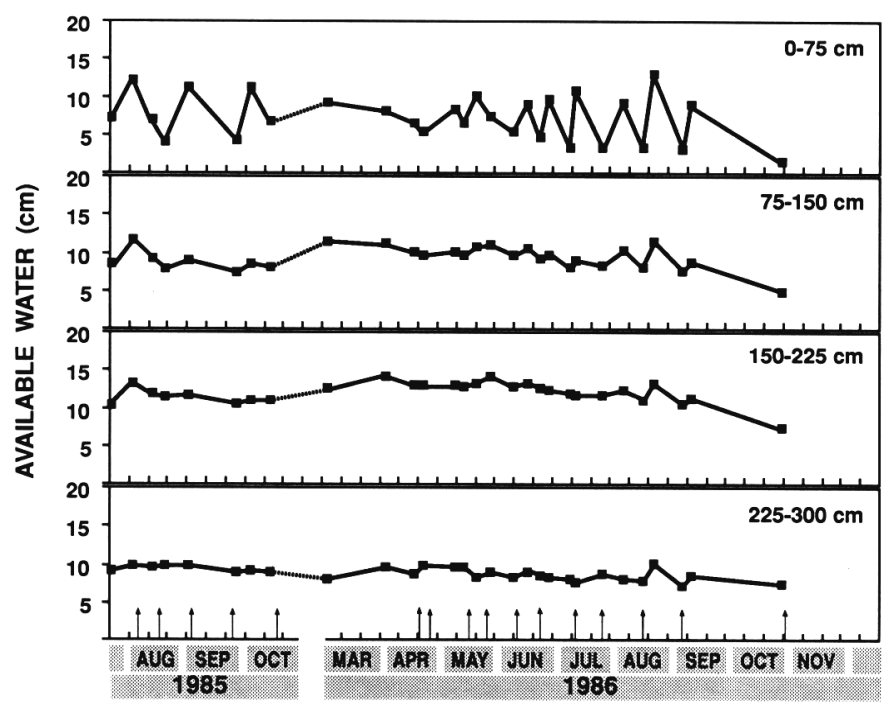

Fig. 4. Pattern of available water content at $75-\mathrm{cm}$ vertical increments of the soil profile over time in response to the control treatment. Symbols represent mean available water content measured at three depths in each increment at six sites. Arrows indicate irrigations.

This was true for the control treatment during the whole season (Fig. 4) and the two deficit treatments before harvest (Figs. 5 and 6). However, as the upper layers of soil began to dry out in the deficit treatments, extraction occurred at increasingly greater depths.

By early August of 1985 and 1986, the trees in the dry treatment had depleted the upper $75 \mathrm{~cm}$ of the soil profile of virtually all available water (Fig. 6). By early September the profile was completely depleted to a depth of $225 \mathrm{~cm}$, and the trees were still extracting water at a depth of $300 \mathrm{~cm}$ (the greatest depth measured). After the early August irrigation, the trees in the medium treatment had totally depleted the top $75 \mathrm{~cm}$ of soil by the end of the season and continued to extract water from greater depths.

\section{Discussion}

Reports in the literature disagree over the effects of water stress on the level of flowering (Brown, 1953; Garcia, 1980; Hartmann and Panetsos, 1961; Jackson, 1969; Mitchell et al., 1984; Moreshet et al., 1983; Nakata and Suehisa, 1969; Uriu, 1964). There may be several explanations for this variation. Species differences might be expected because of the different climatic conditions to which each species is adapted. Degree of stress might also be important, with moderate stress increasing

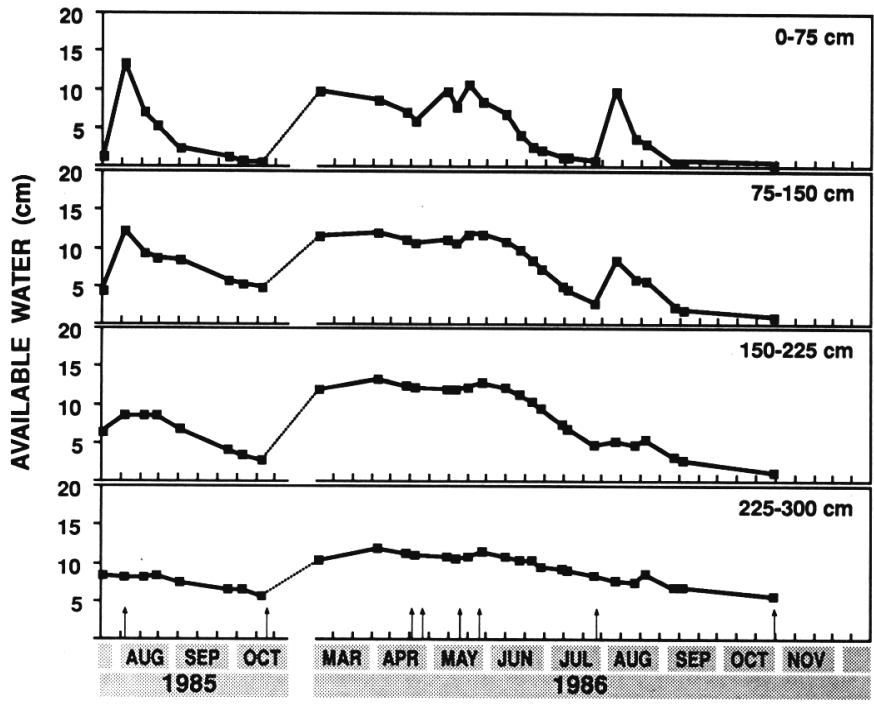

Fig. 5. Pattern of available water content at $75-\mathrm{cm}$ vertical increments of soil profile over time in response to the medium treatment. Symbols represent mean available water content measured at three depths in each increment at six sites. Arrows indicate irrigations.

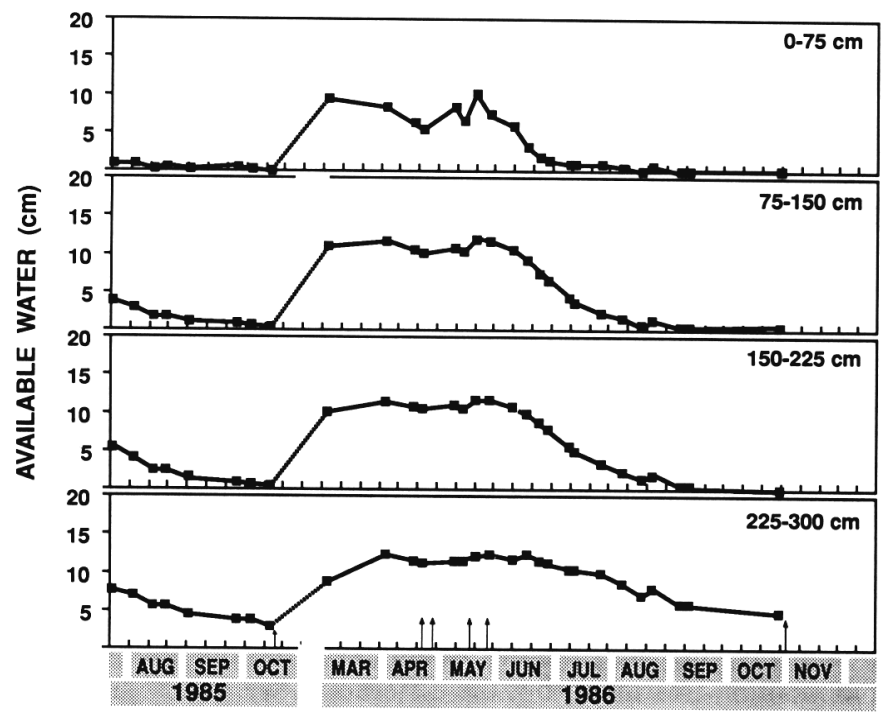

Fig. 6. Pattern of available water content at $75-\mathrm{cm}$ vertical increments of soil profile over time in response to the dry treatment. Symbols represent mean available water content measured at three depths in each increment at six sites. Arrows indicate irrigations.

flowering but very severe stress decreasing it. We have some preliminary data on peach to support this idea. An additional factor may be the timing of stress, with one stage of flowering being more sensitive to stress than another (Kaufmann, 1972).

We suggest that the steady increase in flower density over 4 years in the dry treatment results from some morphogenetically active substance building up in the plant in response to stress. The entire hormonal and assimilate balance of plants is affected by water stress (Hsiao, 1973), including levels of cytokinins (Bradford and Hsiao, 1982) and gibberellins (Hsiao, 1973), both of which have been implicated in floral initiation in fruit trees (Gur, 1985; Hoad, 1984). Water stress has been shown to increase the root : shoot ratio of fruit trees (Cripps, 1971), pos- 
sibly affecting levels of root-produced hormones, such as cytokinins.

Specific polyamines accumulate in response to stress (Flores et al., 1985), and various polyamines have been linked to increased levels of floral initiation in apple (Edwards, 1986; Rohozinski et al., 1986) and pear (Crisosto et al., 1988). Further research on effects of water stress on peach might focus on rootsupplied hormones or polyamines.

In California, peach trees generally produce more flowers than are needed for a commercial crop of adequately sized fruit. Therefore, increased flowering offers no advantages under these conditions. However, there is considerable variation in flower density among cultivars. 'Regina', used in this study, has a flower density considerably lower than that reported for many other commerical cultivars (Byers and Lyons, 1985; Coston et al., 1985). Low flower density has been reported for some cultivars (Irving, 1987), and in some situations increased flowering could increase yields.

Double fruit results from flowers with two carpels (Philip, 1933). Carpel differentiation in peach flower buds has been observed in late August and early September in California (Garcia, 1980; Tufts and Morrow, 1925). The lower amount of double fruit in the deficit treatment receiving an irrigation in early August than in the dry treatment (Fig. 2) suggests that relief of water stress before carpel differentiation reduces double formation. The exact timing of irrigation to relieve water stress needs to be developed further, but a viable management strategy that would reduce consumptive water use, without increasing levels of doubles, appears to be achievable.

Heat stress during the previous summer has been suggested as a major cause of doubling in cherries (Philip, 1933; Tucker, 1934). In this experiment, drought stress significantly increased the level of doubles in all 3 years, but the magnitude of doubling was much higher in 1985 and 1987 than in 1986. The average maximum temperatures during August and, especially, early September were higher in 1984 and 1986 than 1985 (Table 4). This pattern supports the idea that temperature during carpel differentiation may have a major impact on double fruit formation in water-stressed trees.

During the first year of this study, stomatal conductance and transpiration were substantially reduced in the dry treatment (Larson et al., 1988). Reduced transpiration under prolonged high ambient temperatures, high incident radiation, and low wind velocities results in pronounced increases in canopy temperature (Gates, 1968). The increased levels of doubles in response to water deficit may therefore be related to high leaf temperatures, and the higher levels of doubling in 1985 and 1987 may be explained by elevation of already high temperatures due to reduced transpiration.

In this experiment, a shift in the water extraction pattern from the upper soil layers to the lower layers occurred as the soil water in the upper layers was depleted (Figs. 5 and 6). Extraction of total available water to a depth of $300 \mathrm{~cm}$ was recorded in the dry treatment. Levin et al. (1973) and Garnier et al. (1986) only measured depletion to depths of 180 and $120 \mathrm{~cm}$, respectively. Garnier et al. (1986) attributed depletion from the 120 to $180-\mathrm{cm}$ layers to upward fluxes to dryer soil layers, based on limited rooting below the gravel layer. Low root densities were measured to depths of $240 \mathrm{~cm}$ in the current experiment, accounting for the low but steady rate of extraction from 225 to $300 \mathrm{~cm}$. In this study, the shift in extraction patterns occurred with mature furrow-irrigated trees on a well-drained, deep, sandy loam soil. Under conditions that limit the potential root zone, this adjustment might not be possible, or might be less pronounced.

The shift in water extraction pattern in the dry treatment might be expected to lead to a similar shift in root growth, since water depletion has been shown to be proportional to root density (Levin et al., 1973). Root distribution data collected in this experiment showed a trend toward increased root densities at greater depths in dry treatments (Fig. 3) but the distribution did not differ significantly. The small sample size and large variability may have been a factor in the inability to detect significant differences. One factor contributing to this large variability was the wide range of soil textures encountered at a depth of 150 to $200 \mathrm{~cm}$.

The majority of roots in all treatments occurred in the top 90 $\mathrm{cm}$ of the soil profile (Fig. 3). Since this zone was completely depleted of available water in the dry treatment by the end of the season, it is not surprising that this treatment was under severe stress. Larson et al. (1988) showed an almost complete closure of stomata by mid-September in the first year of the study. However, surprisingly, the trees did not show more extreme symptoms of stress, such as defoliation and limb dieback, which have been reported for other fruit trees (Proebsting and Middleton, 1980; Proebsting et al., 1981). Perhaps the few roots deep in the soil profile supplied enough water to keep the trees from experiencing permanent damage due to stress.

The consistent pattern in pruning weight reduction over the 4 years provides more evidence that no permanent damage was inflicted by the dry treatment. The reduction seemed to follow an alternating cycle, showing an insignificant decrease in the first and third years and a $30 \%$ difference in the second and fourth (Table 3). Trunk radial growth was reduced by $38 \%$ and tree shaded area by $13 \%$ in the dry treatments, suggesting a greater effect on radial than extension growth. This relationship would be expected, since extension growth is largely completed by June in mature peach trees (DeJong et al., 1987); but radial growth continues through the season (Gamier and Berger, 1986).

The water stress treatments increased specific leaf weight, as has been reported for several species (O'Connor and Dickman, 1985; Wilson et al., 1987). With only a small reduction in total leaf area as suggested by the $13 \%$ decrease in shaded area, the $23 \%$ increase in specific leaf weight would tend to cancel this out, leading to a fairly constant dry-weight allocation to the leaves of the different treatments.

In conclusion, 4 years of moderate to severe postharvest water stress on the early season peach we tested did not lead to a reduction in yield and fruit size or a progressive decline in tree vigor and health. The major drawback to the practice is a substantial increase in double fruit, leading to increased time-and expense in hand thinning. However, results of this experiment indicate that alleviation of stress by a well-timed irrigation for a short period before carpel differentiation will reduce the occurrence of doubles. Further research should focus on the timing of stress alleviation, with the intent of developing a drought management strategy that will reduce water use while preserving marketable yields.

\section{Literature Cited}

Bertrand, P.F., H. English, K. Uriu, and F. Schick. 1976. Late season water deficits and development of Cytospora canker in French prune. Phytopathology 66:1318-1320.

Bohm, W. 1979. Methods of studying root systems. Springer-Verlag, New York. p. 48-60.

Bradford, K.J. and T.C. Hsiao. 1982. Physiological responses to mod- 
erate water stress, p. 254-324. In: O.L. Lange, P.S. Nobel, C.B. Osmond, H. Ziegler (eds.). Physiological plant ecology II. Water relations and carbon assimilation. Encyclopedia Plant Physiol. vol. $12 \mathrm{~b}$, Springer-Verlag, Berlin/New York.

Brown, D.S. 1953. The effects of irrigation on flower bud development and fruiting in the apricot. Proc. Amer. Soc. Hort. Sci. 61:119124.

Byers, R.E. and C.G. Lyons, Jr. 1985. Peach flower thinning and possible sites of action of desiccating chemicals. J. Amer. Soc. Hort. Sci. 110:662-667.

Coston, D.C., G.W. Krewer, T.E. Elkner, J.G. Williamson and E T Sims, Jr. 198.5. Chemical treatments to delay bloom in peach. J. Amer. Soc. Hort. Sci. 110:874-877.

Cripps, J.E. 1971. The influence of soil moisture on apple root growth and root:shoot ratios. J. Hort. Sci. 46:121-130.

Crisosto, C.H., D. Sugar, and P. Lombard. 1988. Effect of putrescine sprays at anthesis on 'Cornice' pear yield components. Adv. Hort. Sci. 2:27-29.

DeJong, T.M., J.F. Doyle, and K.R. Day. 1987. Seasonal patterns of reproductive and vegetative sink activity in early and late maturing peach (Prunus persica) cultivars. Physiol. Plant. 71:83-88.

Edwards, G.R. 1986. Ammonia, arginine, polyamines and initiation in apple. Acta Hort. 179:63-68.

Flores, H., N. Young, and A.W. Galston. 1985. Polyamine metabolism and plant stress, p. 93-114. In: J.L. Key and T. Kosuge (eds.) Cellular and molecular biology of plant stress. A.R. Liss New York:

Garcia, M.A. 1980. Influence of different irrigation regimes on flower bud formation and development in peach trees. MS Thesis, Univ. of California, Davis.

Garnier, E. and A. Berger. 1986. Effect of water stress on stem diameter changes of peach trees growing in the field. J. Applied Ecol. 23:193-209.

Garnier, E., A. Berger, and S. Rambal. 1986. Water balance and pattern of soil water uptake in a peach orchard. Agr. Water Management 11:145-158.

Gates, D.M. 1968. Transpiration and leaf temperature. Annu. Rev. Plant Physiol. 19:211-238.

Gur, A. 1985. Rosaceae-deciduous fruit trees, p. 355-390. In: A Halevy (ed.). Handbook of flowering, vol. I. CRC, Bota Raton 'Fla'

Hartmann, H.T. and C. Panestsos. 1961. Effect of soil moisture deficiency during floral development on fruitfulness in the olive. Proc. Amer. Soc. Hort. Sci. 78:209-217.

Hoad, C.V. 1984. Hormonal regulation of fruit-bud formation in fruit trees. Acta Hort. 149:13-23.

Hsiao, T.C. 1973. Plant responses to water stress. Annu. Rev. Plant Physiol. 24:519-570.

Irving, D.E. 1987. 'Fantasia' nectarine: Effects of autumn-applied ethephon on blossoming and cropping. N.Z. J. Expt. Agr. 15:6772 .

Jackson, D.I. 1969. Effects of water, light, and nutrition on flowerbud initiation in apricots. Austral. J. Biol. Sci. 22:69-75.
Kaufmann, M.R. 1972. Water deficits and reproductive growth, p. 91-124. In: T.T. Kozlowski (ed.). Water deficits and plant growth, vol. III. Academic, New York.

Larson, K.D., T.M. DeJong, and R.S. Johnson. 1988. Physiological and growth responses of mature peach trees to postharvest water stress. J. Amer. Soc. Hort. Sci. 113:296-300.

Levin, I., B. Bravdo, and R. Assaf. 1973. Relation between apple root distribution and soil water extraction in different irrigation regimes, p. 351-359. In: A. Hadas, et al. (eds.). Ecological studies. Analysis and synthesis, vol. 4. Springer-Verlag, Berlin/New York:

Little, M.T. and F.J. Hills. 1978. Agricultural experimentation: Design and analysis. Wiley, New York.

Mitchell, P.D., P.H. Jerie, and D.J. Chalmers. 1984. The effects of regulated water deficits on pear tree growth, flowering, fruit growth, and yield, J. Amer. Soc. Hort. Sci. 109:604-606.

Moreshet, S., Y. Cohen, and M. Fuchs. 1983. Response of mature 'Shamouti' orange trees to irrigation of different soil volumes at similar levels of available water. Irr. Sci. 3:223-236.

Nakata, S. and R. Suehisa. 1969. Growth and development of Litchi chinensis as affected by soil-moisture stress. Amer. J. Bot. 56:11211126.

O'Connor, J.M. and D.I. Dickmann. 1985. Effects of site stress on water relations and leaf morphology of two hybrid poplar clones in northern Michigan. Mich. Acad. 17:137-140.

Philip, G.L. 1933. Abnormality in sweet cherry blossoms and fruit. Bot. Gaz. 44:815-820.

Proebsting, Jr., E.L. and J.E. Middleton. 1980. The behavior of peach and pear trees under extreme drought stress. J. Amer. Soc. 'Hort. Sci. 105:380-385

Proebsting, Jr., E.L., J.E. Middleton, and M.O. Mahan. 1981. Performance of bearing cherry and prune trees under very low irrigation rates. J. Amer. Soc. Hort. Sci. 106:243-246.

Rohozinski, J., G.R. Edwards, and P. Hoskyns. 1986. Effects of brief exposure to nitrogenous compounds on floral initiation in apple trees. Physiol. Veg. 24:673-677.

Ryugo, K. 1988. Fruit culture: Its science and art. Wiley New York.

Tucker, L.R. 1934. Notes on sweet cherry doubling. Proc. Amer. Soc. Hort. Sci. 31:300-302.

Tufts, W.P. and E.B. Morrow. 1925. Fruit bud differentiation in deciduous fruits. Hilgardia 1:3-14.

Tyree, M.T. and M.A. Dixon. 1986. Water stress induced cavitation and embolism in some woody plants. Physiol. Plant. 66:397-405.

Uriu, K. 1964. Effect of postharvest soil moisture depletion on subsequent yield of apricots. Proc. Amer. Soc. Hort. Sci. 84:93-97.

Veihmeyer, F.J. 1975. The growth of fruit trees in response to different soil moisture conditions measured by widths of annual rings and other means. Soil Sci. 119:448-460.

Wilson, R.F., J.J. Burke, and J.E. Quisenberry. 1987. Plant morphological and biochemical responses to field water deficits. Plant Physiol. 84:251-254. 